\title{
Sonographic Measurments of Portal Vein Diameter in Normal Indian Children in Relation to Age, Weight and Height
}

\author{
Sunil Chandrasen Chand ${ }^{1}$, Janki Bharatkumar Jaradi ${ }^{2}$ \\ ${ }^{1}$ Assistant Professor, Department of Pediatrics, AMC MET Medical College, Ahmedabad, ${ }^{2}$ Assistant Professor, Department of \\ Radiology, AMC MET Medical College, Ahmedabad, India \\ Corresponding author: Dr. Janki Bharatkumar Jaradi, 6/12, Umasut Flats, Opposite Godavari Nagar Part 1, Vasna, Ahmedabad, \\ 380007, India
}

DOI: http://dx.doi.org/10.21276/ijcmsr.2019.4.3.29

How to cite this article: Sunil Chandrasen Chand, Janki Bharatkumar Jaradi. Sonographic measurments of portal vein diameter in normal indian children in relation to age, weight and height. International Journal of Contemporary Medicine Surgery and Radiology. 2019;4(3):C128-C134.

\section{A B S T R A C T}

Introduction: The assessment of portal vein size by ultrasonography is an important noninvasive investigation which supports the diagnosis of portal hypertension in children and adults. Indian data regarding normal portal vein diameter in children are sparse. Present study was undertaken to establish normal range of portal vein diameter in children in relation to age, weight and height.

Material and methods: During September 2015 to May 2018, a prospective study of 148 patients was carried out in the department of paediatrics and radiology at L.G.Hospital, Ahmedabad between the age group of day 1 of life to 15 years, residing in Gujarat and adjacent areas of MP and Rajasthan. The measurement of portal vein diameter at porta made during quiet breathing in younger children and during breath-holding in older children. Neither preparation nor sedation was used. Results: Portal vein diameter highly correlated with each of the variables: age, height, weight. The correlation observed was all similar in magnitude and highly significant $(P<0.0001)$. Most statistically significant correlation with portal vein diameter was observed with height. The mean portal vein diameter increased with height.

Conclusion: Most statistically significant correlation with portal vein diameter was observed with height. The mean portal vein diameter increased with height.

Keywords: Ultrasonography (USG), Portal vein (PV)

\section{INTRODUCTION}

The assessment of portal vein size by ultrasonography is an important noninvasive investigation which supports the diagnosis of portal hypertension in children as there is association between portal vein dilatation and portal hypertension and a child who needs liver transplant. Indian data regarding normal portal vein diameter in children are sparse. Ultrasonography is a well-established method of demonstrating the portal vein. Liver cirrhosis and portal vein thrombosis are the main cause of portal hypertension in children. The idea of doing this study is to give baseline data of diameter of portal vein in different age groups. It may be helpful in performing ultrasonography which can be used as a screening tool in investigating a case of portal hypertension. Real-time gray-scale sonography has made it possible to evaluate the portal vein rapidly, reliably, inexpensively and noninvasively. Investigations other than sonography are mostly invasive and time consuming and aren't helpful for screening. Also they are associated with small but inherent risks of mortality and morbidity and they are thus unacceptable as screening procedures for portal hypertension. Present study was undertaken to establish normal range of portal vein diameter in children in relation to height, weight and age.

Study aimed to evaluate normal portal vein diameter at porta from day 1 of Life to 15 years of life in male and female children, to know the correlation between the normal portal vein diameters with parameters such as age, weight, and height in children and to compare our study with other similar studies in other states of India and other countries.

\section{MATERIAL AND METHODS}

During the period of September- 2015 to June 2018 a prospective study of 148 patients was carried out in the department of paediatrics at L.G.Hospital, Ahmedabad. Total 148 participants were enrolled in our study between the age group of day 1 of life to 15 years, residing in Gujarat and adjacent areas of MP and Rajasthan. Informed and verbal consent was obtained from the accompanying guardians/ parents of all children, and verbal consent taken from all children older than 5 year. Baseline data including the age, weight, height and body mass index were recorded for all the children in a structured Performa. An electronic weighing scale and a wall mounted stadiometer (1 mm markings) were used to measure the weight $(\mathrm{kg})$ and height $(\mathrm{cm})$, as per standard methodology. ${ }^{13}$ The body mass index ${ }^{13}$ was 
calculated. All the children underwent an ultrasonographic assessment of the liver, spleen and portal vein diameter by using a GE Logiq P5 system. The measurement of portal vein diameter at porta made during quiet breathing in younger children and during breath-holding in older children. Neither preparation nor sedation was used.

\section{Inclusion Criteria}

1. All children (male and female) between age $1^{\text {st }}$ day of Life to 15 years who is not having any hepatobiliary complaints in the past or present.

2. Parent or guardian's willing to give consent to participate in study.

\section{Exclusion Criteria}

1. Any child under evaluation for/ follow-up case of a condition which could affect the size of the liver, spleen or portal vein e.g. viral hepatitis, malaria, portal hypertension, haemolytic anaemia, enteric fever, congestive heart failure and malnutrition was not included in the study.

2. Children less than 24 hours of Life and more than 15 years of age.

3. All critical patients admitted in paediatric intensive care unit.

4. Moderate to severe malnourished children with weight and height less than 2SD as per WHO 2006 had been excluded from the study.

5. Parents not willing to provide consent.

\section{RESULTS}

The sample size of 148 cases was divided into 5 age groups: 0-7 days of life, at $1 \mathrm{yr}$ of life, at 5 yrs of life, at 10 years of life (early adolescence age) and at 15 years (middle adolescence) respectively. In each age group, number of female and male children was calculated. The observations as represented in the above bar diagram are:

In 1-7 days, Female children $=16$, male children $=14$, Total $=30$

At 1 year, Female children $=15$, male children $=15$,
Total $=30$

At 5 years, Female children $=15$, male children $=14$, Total $=29$

At 10 years, Female children $=16$, male children $=14$, Total $=30$

At 15 years, Female children $=15$, male children $=14$, Total $=29$

In all the age groups, the number of female children is greater compared to male children. This may be due to the poor general conditions of females.

Distribution of population according to Sex

There are 72 males (49\%) and 76 females (51\%) included in the study with equal distribution of baseline parameters in each group.

In females, $\mathrm{n}=76$

Mean age $=6.18$, mean height $=1.023$, mean

weight $=18.03$

Mean BMI = 14.80,

In males, $\mathrm{n}=72$

Mean age $=6.30$, mean height $=1.039$, mean weight $=19.23$

Mean BMI = 15.26,

The figure- 1 shows portal vein diameter in both genders in respective age group it was observed that the portal vein diameter increases with age, $\mathrm{p}<0.0001$. Average portal vein diameter in males was $6.959 \pm 2.288$ and average portal vein diameter in females was $6.628 \pm 1.864$.

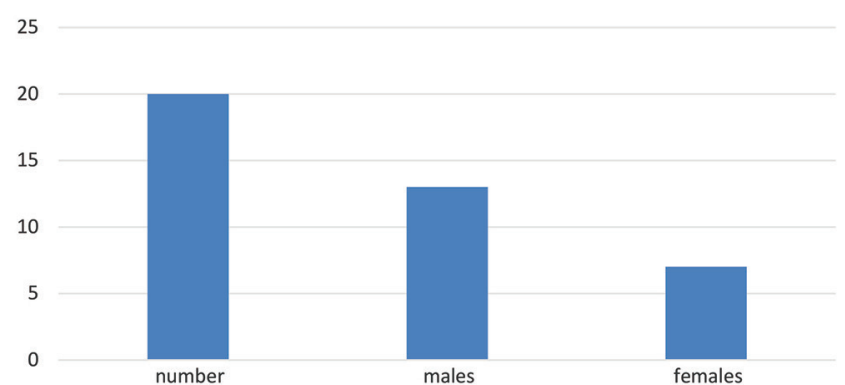

Figure-1: Distribution of the mean portal vein diameter $(\mathrm{mm})$ according to Age and Sex.

\begin{tabular}{|c|c|c|c|c|c|c|c|c|c|c|}
\hline \multirow{2}{*}{$\begin{array}{l}\text { Height } \\
\text { (cms) }\end{array}$} & \multirow[b]{2}{*}{ Mean } & \multirow[b]{2}{*}{ SD } & \multirow{2}{*}{\multicolumn{2}{|c|}{ Range }} & \multicolumn{6}{|c|}{ Percentiles } \\
\hline & & & & & 10 & 25 & 50 & 75 & 90 & 95 \\
\hline $40-60$ & 3.7655 & 0.465 & 3.10 & 3.588 & 3.20 & 3.40 & 3.80 & 4.00 & 4.50 & 4.65 \\
\hline $61-80$ & 5.3200 & 0.609 & 4.562 & 4.60 & 4.60 & 4.70 & 5.40 & 5.90 & 6.0 & 6.40 \\
\hline $81-100$ & 6.7882 & 0.622 & 6.468 & 6.00 & 6.00 & 6.10 & 6.80 & 7.20 & 7.80 & 8.10 \\
\hline $101-120$ & 6.9697 & 0.727 & 6.745 & 6.02 & 6.14 & 6.40 & 6.80 & 7.40 & 8.00 & 8.80 \\
\hline $121-140$ & 7.2043 & 0.741 & 6.883 & 6.08 & 6.40 & 6.60 & 7.00 & 8.00 & 8.00 & 8.80 \\
\hline $141-172$ & 9.490 & 1.635 & 8.879 & 7.39 & 8.00 & 8.45 & 9.20 & 10.40 & 10.98 & 13.25 \\
\hline
\end{tabular}

\begin{tabular}{|l|c|c|c|c|c|}
\hline Age group & $\mathbf{N}$ & Mean weight (kg) & Std. Deviation & \multicolumn{2}{c|}{ Range (Minimum- Maximum) } \\
\hline 1-7 days & 30 & 2.833 & 0.434 & 1.6200 & 3.6000 \\
\hline At 1 yr life & 29 & 13.331 & 4.146 & 5.0000 & 25.0000 \\
\hline At 5 yrs life & 29 & 14.693 & 2.679 & 10.0000 & 25.0000 \\
\hline At 10 yrs life & 30 & 24.833 & 3.152 & 20.0000 & 34.0000 \\
\hline At 15 yrs life & 30 & 37.320 & 7.668 & 24.0000 & 50.0000 \\
\hline Total & 148 & 18.664 & 12.526 & 1.620 & 50.000 \\
\hline \multicolumn{2}{|r|}{ Table-2: Portal vein diameter $(\mathrm{mm})$ percentiles according to weight. } \\
\hline
\end{tabular}




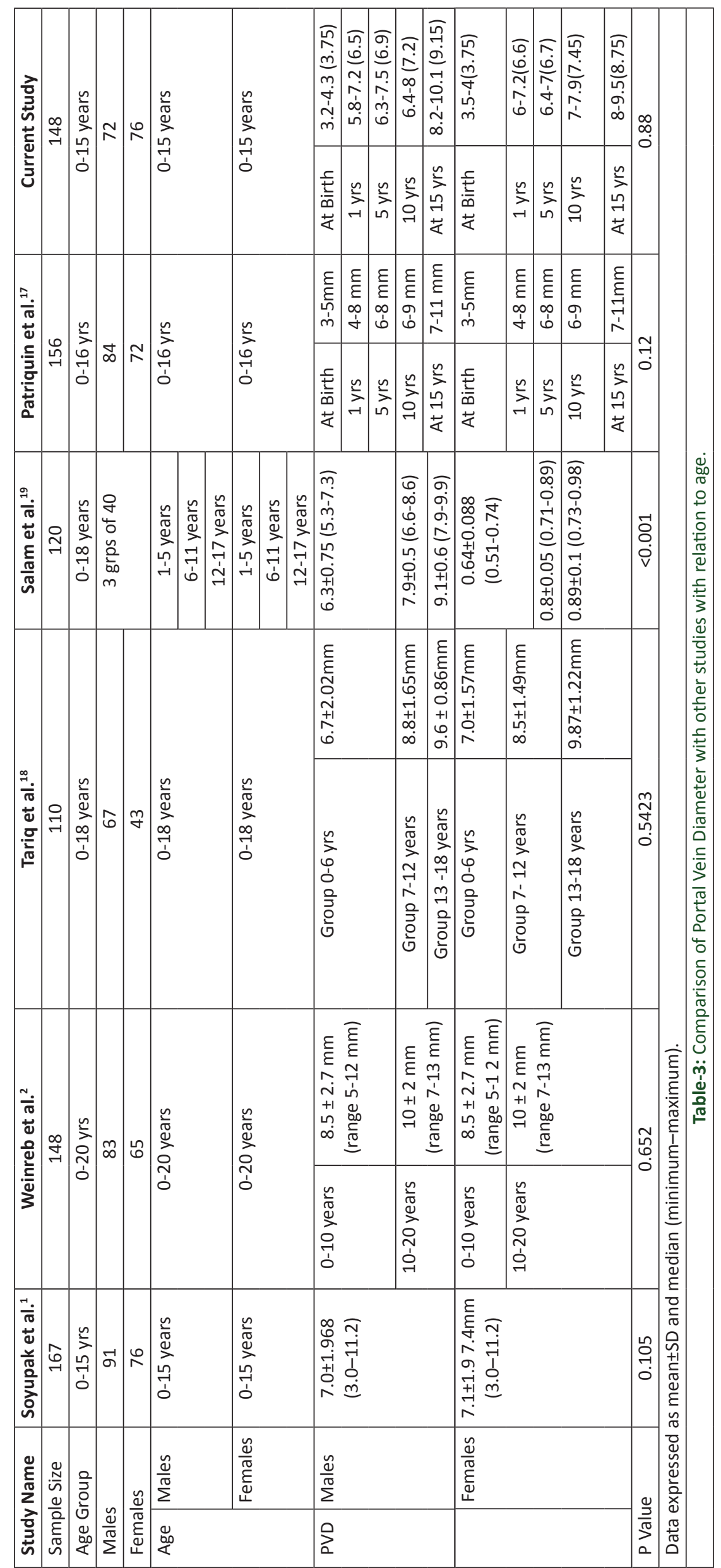




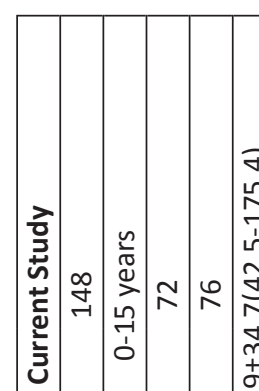

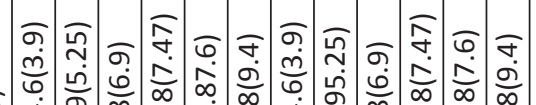

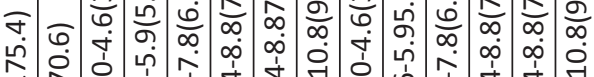

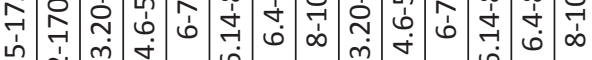

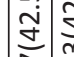

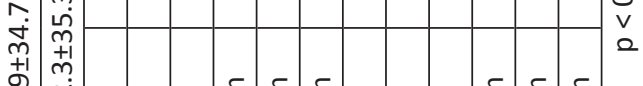

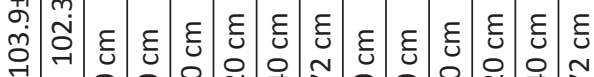

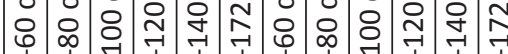

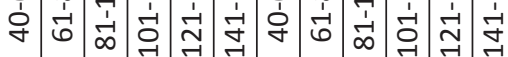

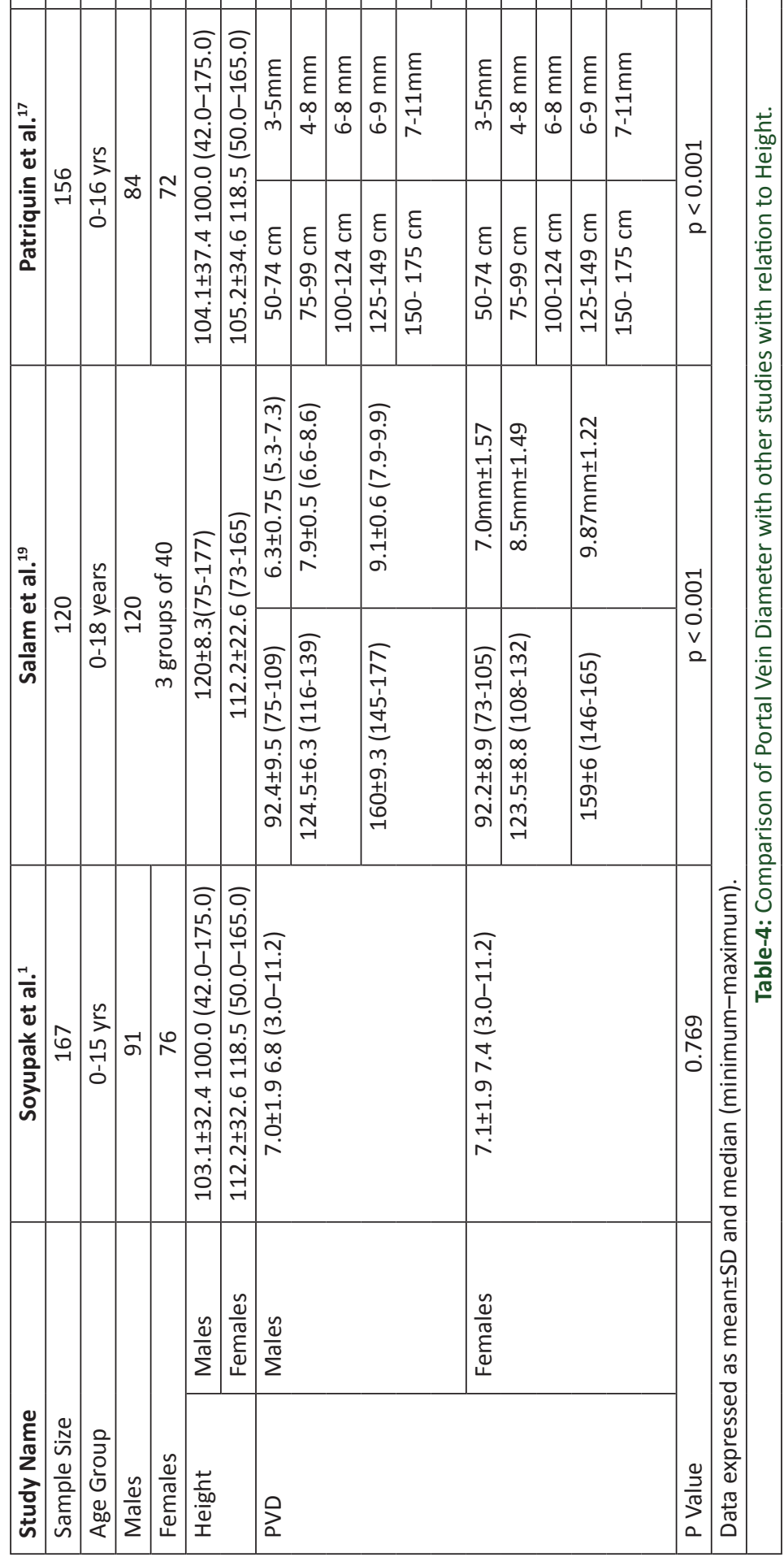
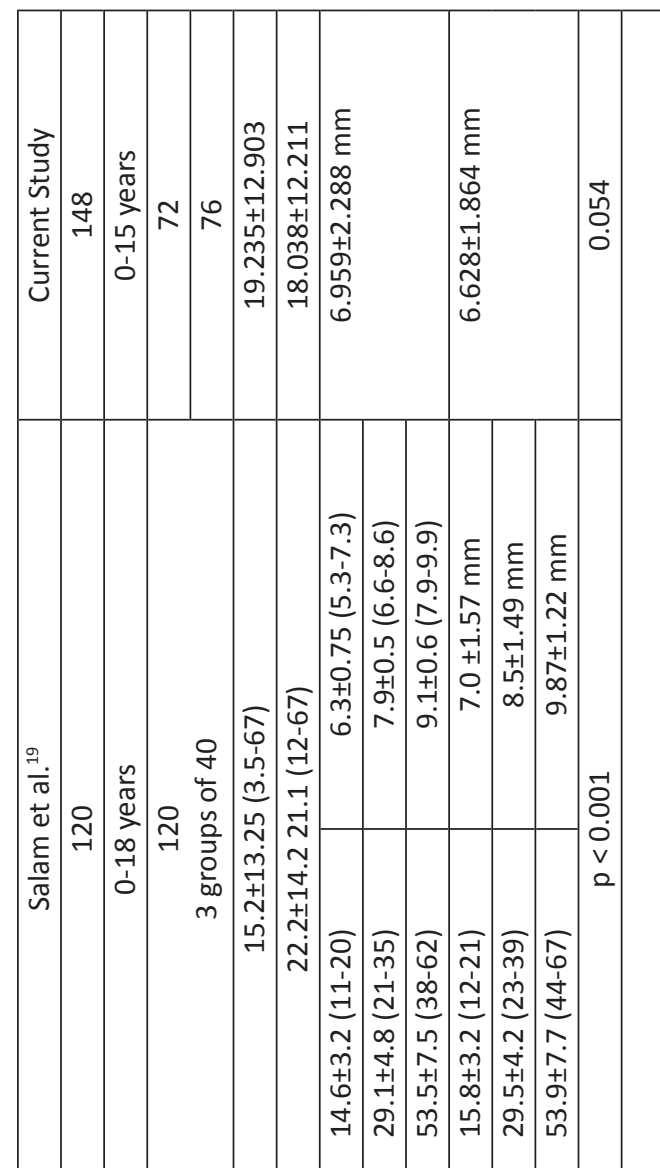

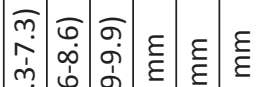

ம்

茥

$\stackrel{+}{\div}$ $\sum_{0}^{\infty}$

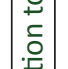
$\frac{\pi}{2}$ 䍃

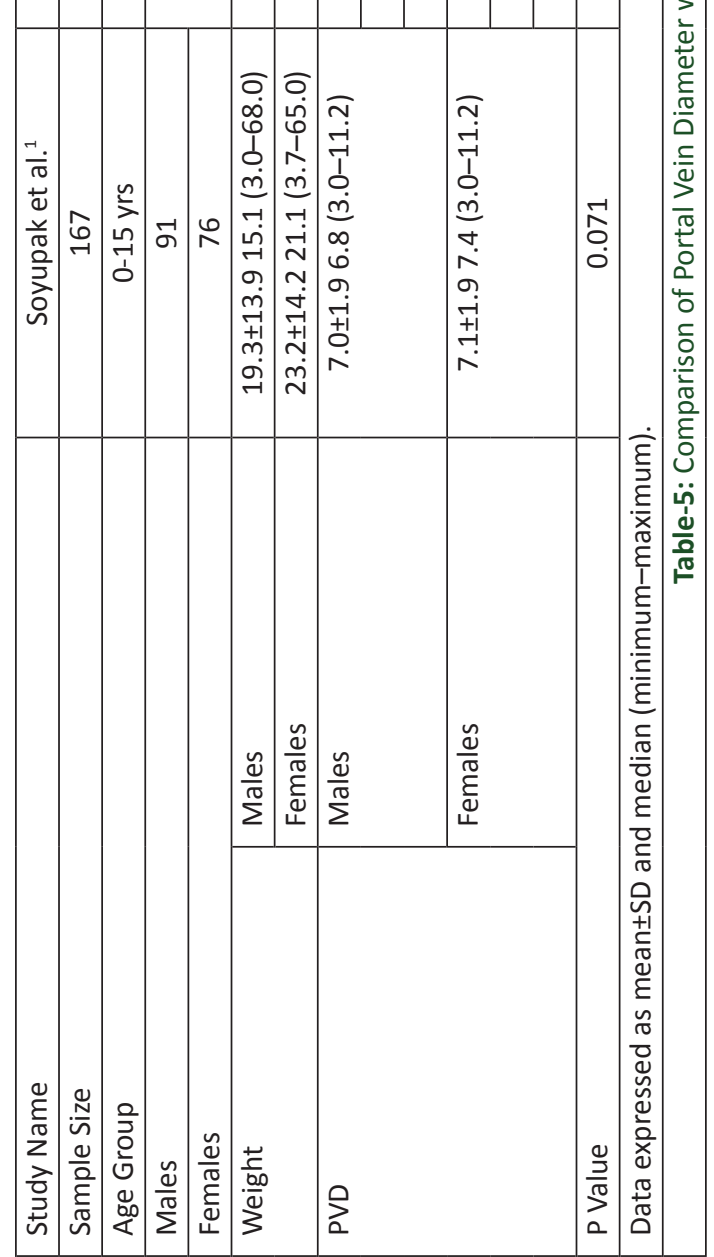


The table- 1 shows the PVD with respect to height. It was observed that with increasing height the PVD also increases significantly

The table-2 describes the range of portal vein diameter with respect to weight. It was observed in our study that with increasing weight the PVD also increases as observed in the Table-2.

\section{DISCUSSION}

The observations of the present study are compared here along with the available literature from past. Our results are comparable to these studies. There have been quite a few previous reports giving the standard sizes of portal vein diameter by ultrasound in children, but none has been done in this part of country (table-3).

\section{Portal vein diameter with relation to Age.}

Average total in our Study:

Male: $6.9 \pm 2.2 \mathrm{~mm}$

Female: $6.6 \pm 1.8 \mathrm{~mm}$

The studies taken for comparison have almost similar baseline characteristics with respect to age and sex distribution. All the studies had similar findings with respect to age that is with increasing age the portal vein diameter also increases whereas in context of gender most studies found almost no difference in portal vein diameter between male and female. According to Soyupak ${ }^{1}$, Knowledge of normal portal dimensions is important in diagnosing and monitoring hepatobiliary disorders in childhood. These values are better established in adults. It has been published in several studies that portal dimensions are slightly larger in men, increases slightly with inspiration, decreases with exercise and in upright position. ${ }^{1,2,3,4,5}$ Studies in the pediatric age group are limited. In our study, measurements were taken under standard conditions: patients in supine position, while quiet breathing and at least two hours after a normal meal. It was found that the results obtained in our study were comparable to what Soyupak ${ }^{1}$ found the average PVD found in his study in male population was $7.0 \pm 1.968 \mathrm{~mm}$ and in female population it was $7.1 \pm 1.974 \mathrm{~mm}$, our study had similar comparable values $6.959 \pm 2.288 \mathrm{~mm}$ in males and $6.62 \pm 1.864$ $\mathrm{mm}$ in females.

When compared to Patriquin et al.'s study, one of the first and major papers on normals for portal diameter in children, we found similar values for similar age groups that are at birth the PVD was $3-5 \mathrm{~mm}$, At 1 year 4-8 $\mathrm{mm}$, at 5 years 6-8 $\mathrm{mm}$, at 10 years $5-9 \mathrm{~mm}$ and at 15 years $7-11 \mathrm{~mm}$ and in our study at birth PVD was $3.2-4.3 \mathrm{~mm}$ at birth, 5.8-7.2 at 1 year, 6.3-7.5 at 5 years, $6.4-8$ at 10 years and 8.2-10.1 at 15 years, the findings were comparable to our study as average of both studies were almost similar. However, in our study there was no gender difference whereas Patriquin et al. ${ }^{6}$ reported a slight difference between boys and girls. That could be due to different ethnic groups and populations which took part in the study. Vocke et al. ${ }^{7}$, on the other hand, did not find any gender difference, and our diameter values are consistent with their results. They also concluded that although both age and height correlate well with portal vein diameter, cutoff values should be related to body height rather than age. ${ }^{1}$ We have come up with the same conclusion as shown on
Table 1. As stated previously, it is of utmost importance to establish the normal's first in order to recognize and monitor the abnormal. These normal values for portal vein diameter in the pediatric age group will be useful in diagnosing and following hepatobiliary diseases of childhood.

With comparison to Weinreb ${ }^{2}$, there was no difference between the portal venous measurements of male and female patients. When compared to our study in the age group of 0-10 years the range of PVD was $5-12 \mathrm{~mm}$ in Weinreb $^{2}$ and our study showed a range of 3.2-8 $\mathrm{mm}$, the variation could be due to difference in ethnicity of the participants. However it was observed that with increasing age the portal vein diameter also increases with a significant correlation $(\mathrm{p}<0.0001)$.

Normal portal venous dimensions in adults are well known. In a study where the portal vein diameter was calculated as in this study, the portal vein was slightly larger in men (9.2$122 \mathrm{~mm}$ Vs. 7.9-10.2 $\mathrm{mm}$ in woman), and increased slightly in inspiration. ${ }^{7}$ Portal venous flow increases after a meal and decreased with exercise and in upright position. ${ }^{26}$ Our study was therefore done under relatively standard conditions, usually encountered in the routine abdominal sonographic examination in children; the patient has eaten normally, is at rest in supine position and breathing quietly. We found that attempts to measure portal vein in inspiration and expiration in babies and small children was fruitless. Older children in their attempt to hold their breath in inspiration or expiration often performed a Valsalva maneuver, sometimes increasing the diameter of their portal vein. The portal vein forms a transverse oval in cross section, thus the depth of the vein (anteroposterior diameter) measures sonographically does not necessarily correspond to its width measured angiographically. In addition, at sonography, care must be taken to obtain the largest diameter possible, as that is the only assurance that the cut was taken near the centre of the vessel.

Despite these limitations, this study provides a baseline of normal portal venous dimensions in children.

As in study by Tariq et $\mathrm{al}^{8}$, a correlation was noted between the diameter of portal vein and age. His study demonstrated that the diameter of portal vein increases with increasing age which is similar to the results in a study conducted by Claus Niederau et $\mathrm{al}^{9}$ a positive correlation was also established between age and velocity of portal vein in his study[r]. Tariq et $\mathrm{al}^{8}$ found that in Age Group of 0-6 years the PVD in males was $6.7 \pm 2.02 \mathrm{~mm}$ and in female's $7.0 \pm 1.57 \mathrm{~mm}$, Age Group $7-12$ years, males $8.8 \pm 1.65 \mathrm{~mm}$ and females $8.5 \pm 1.49 \mathrm{~mm}$ and Group C 13-18 years, Males $9.6 \pm 0.86 \mathrm{~mm}$ and Females $9.87 \pm 1.22$, Compared to our studies the values were almost similar.

As per Salam ${ }^{10}$, All US measurements showed non significant ( $p>0.05)$ difference between males and females; indicating minor gender influence on normal growth. On contrary, categorization of study population showed progressive significantly $(p<0.001)$ higher measurements with advance of age in all obtained measurements. The overall findings of Salam ${ }^{10}$ were comparable to our study as shown in Table 1.

Comparisons with other studies, it was found that there was little variation between the genders but there was a significant 
increase in portal vein diameter with increasing age in both sexes (table-4).

Both the studies Soyupak ${ }^{1}$ and Patriquin ${ }^{6}$, showed that Body height is a better indicator for cut-off values for portal vein diameter than age (Table 2). Normal diameter of portal vein related to body height and age can be predicted with high confidence. He found in his study that in both genders with increasing height there was increase in PVD.

Study done by Salam et $\mathrm{al}^{10}$, all obtained US measurements showed a positive significant correlation with age, weight and height. However, PVD showed their highest correlation coefficient with height $(\mathrm{r}=0.808$ and 0.861 , respectively, $\mathrm{p}<0.001)$. There was non-significant difference in estimated parameters between males and females; a finding indicated that no impact of sex on the natural growth process manifested as these measurements. Salam et $\mathrm{al}^{10}$ and our studies were comparable in the context that with increasing height, the PVD also increases. The values obtained in Salam were $0-6$ years, Males PVD is $6.3 \pm 0.75 \mathrm{~mm}$ and in Females $7.0 \pm 1.57 \mathrm{~mm}$ and in our study $0-5$ year's age group PVD was $5.05 \pm 0.80 \mathrm{~mm}$

in males and $5.35 \pm 0.78 \mathrm{~mm}$. The results were comparable. Comparisons with other studies we concluded that Despite age was found to be the main determinant of growth rate of PV, body height was the most significant determinant for PVD (table-5).

As in Soyupak ${ }^{1}$, Diameter of the portal vein increases with the age, weight and height of the child, with a similar correlation with all in both genders. The findings were comparable to our study. In males with weight range of $19.3 \pm 13.9$ (3.0-68.0), Portal vein diameter was 4.2-9.9 $\mathrm{mm}$ and in Females with weight of $22.2 \pm 14.221 .1$ (12-67) PVD was 7.1 \pm 1.97 .4$ (3.0-11.2).

Salam ${ }^{10}$ did showed a positive correlation with weight but according to his study highest correlation coefficient was with height. He found that In males with weight range of $15.2 \pm 13.25$ (3.567), Portal vein diameter was 7.0 1.9 (3.011.2) and in Females with weight of 23.2 \pm 14.2 (3.7-65.0), PVD was $7.1 \pm 1.97 .4$ (3.0-11.2).

In our study it was found that Males with weight of $19.235 \pm 12.903$ and females with weight range of $18.038 \pm 12.211$ had a PVD of $6.959 \pm 2.288$ and $6.628 \pm 1.864$ respectively. The results are comparable to both the above studies with similar findings.

\section{CONCLUSION}

In the present study an attempt has been made to determine the normal range of portal vein diameter and to correlate this with the age, sex, height, and weight. Most statistically significant correlation with portal vein diameter was observed with height. The mean portal vein diameter increased with height. Establishing normal parameters is mandatory for defining the pathologic changes in size of the liver, portal vein, spleen, and kidneys in routine sonographic examinations of children. The methods of measurement and analysis we used in this study are standardized and easy to apply, handy and reliable and are suitable particularly for radiology and pediatric departments. The results of this study can be used as a practical and comprehensive guide to indicate the normal portal vein diameter range for every child, according to his/ her age and body habitus and to analyze whether there is actual dilation or obstruction. Knowing the normal's for portal venous diameter in every age group in children is mandatory in differentiating disease. We believe that the results of this study can be used as a practical and comprehensive guide to indicate the normal range of portal vein diameter for every child, according to his/ her age and body habitus.

\section{Limitations}

- Portal vein diameter changes during respiration; we found that attempts to measure the portal vein in inspiration and expiration in babies and small children difficult.

- Inter observer variations between sonologist.

- Study wasn't compared with children having portal hypertension to actually compare the reliability of the measurement and define exact cut offs for portal hypertension.

\section{REFERENCES}

1. Soyupak S, Gunesli A, Seydaoğlu G, Binokay F, Celiktas M, Inal M.Portal venous diameter in children: normal limits according to age, weight and height. Eur J Radiol, 2010; 75(2):245-7.

2. Jeffry Weismeb, Sheila Kumari, Gasil Philips, Rubem Pochaczvesky. Portal Vein Diameter by Real Time Sonography.AJR 1982; 139:407-499.

3. N. Rahim and E. J. Adam. Ultrasound demonstration of variations in normal portal vein diameter with posture. 1985, The British Journal of Radiology, 1985;58:313314.

4. E. A. Bellamy, M. C. Bossi, M.D. and D. O. Cosgrove. Ultrasound demonstration of changes in the normal portal venous system following a meal. 1984, The British Journal of Radiology 1984;57(2):147-149.

5. Haag K, Rössle M, Ochs A, Huber M, Siegerstetter V, Olschewski M, Berger E, Lu S. Blum HE. Correlation of Duplex Sonography findings and portal pressure in 375 patients with portal hypertension.AJR Am J Roentgenol. 1999; 172(3):631-5.

6. H.B. Patriquin, G. Perreault, A. Grignon, J. Boisvert, D. Filiatrault, L. Gaurel and H. Blanchard. Normal portal venous diameter in children. Pediatr Radiol 1990;20(6): 451-453.

7. Kurol M, Forsberg L. Ultrasonographic investigation of respiratory influence on diameters of portal vessels in normal subjects. Acta Radiol Diagn 1986; 27(3): 675

8. Y Hawaz, D Admassie, $\mathrm{T}$ Kebede. Ultrasound Assessment of Portal Vein Diameter Normal in Ethiopians Done at TikurAnbessa Specialized Hospital. East and Central African Journal of Surgery. Volume 17, No 1 (2012)

9. Fredrick J Suchy, Ronald J Sokol, Williams F Balistreri. Liver Diseases in Children. (2 ${ }^{\text {nd }}$ edition). Section 1; Chapter 6 Portal Hypertension (129-155)

10. Ravi Shankar.G Shailaja Shetty, Srinath.M.G, Roopa Kulkarni . Estimation of Portal Vein Diameter in co Relation with the Age, Sex and Height of An Individual. Anatomica Karnataka 2011;5 (2):13-16.

11. Kara Rye,RobertScott, GerriMortimore,Adam Lawson, 
Andrew Austin, and Jan Freeman towards Non-invasive Detection of Oesophageal Varices. International Journal of Hepatology. Volume 2012 (2012), Article ID 343591, 9 pages; doi:10.1155/2012/343591

12. Graziela C. M. SchettinoI; Eleonora D. T. FagundesII; Mariza L. V. RoqueteIII; Alexandre R. FerreiraIV; Francisco J. PennaV.Portal vein thrombosis in children and adolescents.J. Pediatr. (Rio J.) 2006;82(3).

13. BoyerTD, Wright T, Manns M. Zakim D, editor. Zakim and Boyer's Hepatology. A textbook of liver disease. 5th ed. Philadelphia PA, USA: Saunders, Elsevier; 2006.

14. Pugh RN, Murray-Lyon IM, Dawson JL, Pietroni MC, Williams R. Transection of the oesophagus for bleeding oesophageal varices. Br J Surg. 197;60(8):646-9.

15. Pariente D, Franchi-Abella S: Paediatric chronic liver diseases: how to investigate and follow up? Role of imaging in the diagnosis of fibrosis. Pediatr Radiol 2010, 40(5):906-919. This article is an excellent overview of various imaging techniques for chronic liver disease specifically in children.

16. McKiernan PJ, Sharif K, Gupte GL: The role of endoscopic ultrasound for evaluating portal hypertension in children being assessed for intestinal transplantation. Tranplantation 2008, 86(1):1470-1473.

17. Cales P, Zabotto B, Meskens C, et al.: Gastroesophageal endoscopic features in cirrhosis. Gastroenterology 1990; 98(3):156-162.

18. North-Italian Endoscopic Club for the study and treatment of esophageal varices: Prediction of the first variceal hemorrhage in patients with cirrhosis of the liver and esophageal varices. A prospective multicenter study. N Engl J Med 1988;319(5):983-989.

19. Duché M, Ducot B, Tournay E, et al.: Prognostic value of endoscopy in children with biliary atresia at risk for early development of varices and bleeding. Gastroenterology 2010 (Epub ahead of print).

20. Amna Tariq, Saira Rehman, Ghazala Hanif, Abid Ali Qureshi. Portal Vein Parameters in Pediatric Age Group Using Real Time Sonography and Doppler Ultrasound. Pak Paed J 2012; 36(3): 146-51.

21. Gamal Abdel Salam, Esam Mehlab and Ali Mohamed Ali. Ultrasonographic Estimation of Age-Dependent Changes in Length of Spleen and Hepatic Lobes and Diameters of Portal Vein and Common Bile Duct in Children. Journal of American Science 2013; 9(11):2329.

Source of Support: Nil; Conflict of Interest: None

Submitted: 25-07-2019; Accepted: 10-08-2019; Published online: 04-09-2019 